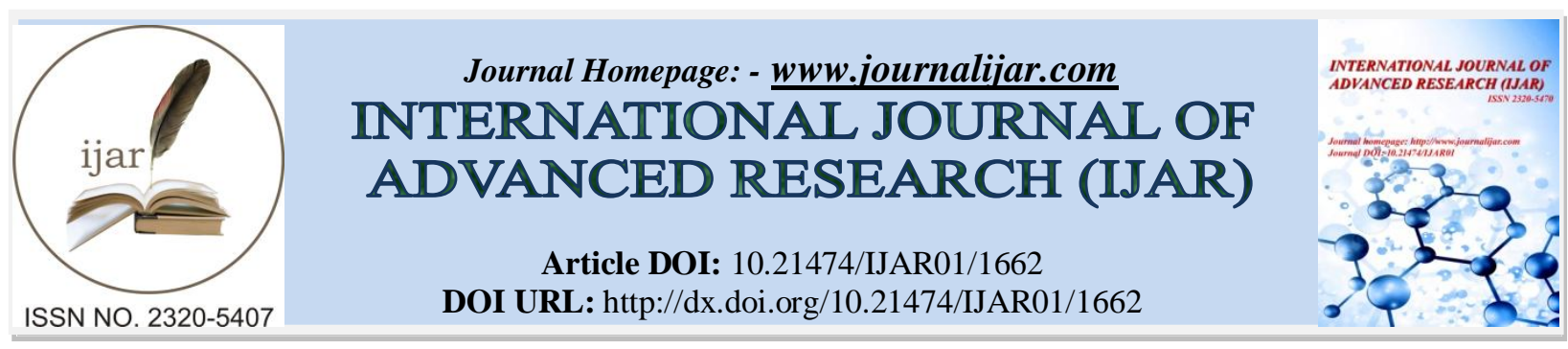

RESEARCH ARTICLE

\title{
PROBLEMS TRANSBOUNDARY POLLUTION IN CENTRAL ASIA.
}

\author{
Juraeva Nigora Amanullahanovna. \\ Senior science researcher at, Tashkent state university of Law, LL.M.
}

\section{Manuscript Info}

Manuscript History

Received: 13 July 2016

Final Accepted: 12 August 2016

Published: September 2016

\section{Key words:-}

Natural resources, the destabilization of the biosphere, environmental safety, air pollution, and environmental cooperation.

\section{Abstract}

In this article considered the issues of global environmental pollution, the goal of improving the effectiveness of environmental protection and ensuring environmental security in Central Asia.

Related environmental problems are not limited to a certain area, only one country or region, destruction of the environment, not knowing the boundaries, without selecting a country, affects all mankind. Especially aggravated environmental problems of recent decades, in particular, humanity suffers from air pollution, water shortages, soil change, extinction of rare species of plants and animals, as well as from anthropogenic increase in atmospheric temperature. Environmental problems have gone beyond the limits of national and regional community has become a universal problem.

Mankind when facing economic, social and political difficulties, it also reflects a deep and on environmental issues. Modern environmental problems compromising the ability of future sustainable development of civilization. The ongoing degradation of natural systems leads to destabilization of the biosphere, the loss of its integrity and ability to maintain the quality of the environment necessary for the normal functioning of society.

"A good example - evidence of our irresponsible attitude towards environmental issues - is the tragedy of the Aral Sea, which is almost only during the lifetime of one generation, has turned from once one of the most unique and most beautiful seas into a drying and vanishing water reservoir. For forty years, the Aral Sea has shrunk by more than 7 times the volume of water decreased 13 times, ten times its increased salinity, making the sea improper place for living organisms; as a result there was a complete degradation and disappearance of almost all species of flora and fauna. Today, the Aral Sea region in the difficult complex of not only environmental, but also social, economic and demographic problems of planetary consequences ..." 1 .

${ }^{1}$ I.A. Karimov The report at the plenary session of the UN Summit Millennium Development Goals. " Narodnoe Slova", September 22, 2010.

Corresponding Author:- Juraeva Nigora Amanullahanovna.

Address:- Senior science researcher at, Tashkent state university of Law, LL.M. 
Recently the site Earth Observatory the National Aeronautics and investigation of the United States Space Administration (NASA) released a fresh satellite image of the Aral Sea, which shows that the eastern part of the South Aral Sea has dried completely and it was the first time in modern history ${ }^{2}$.

It should be noted that the environmental issues that have emerged over the last fifty years, both worldwide and in Central Asia, when they acquire the critical nature of the year, then the international community should be deeply and worry about them. Central Asia - a region in which intersects East and West, is closely intertwined and coexist different cultures and religions, in terms of historical and cultural values takes a worthy place in the world civilization and in it today there are more than 55 million people and the international community. Recognized the sanctity and inviolability of the human rights to life, then that recognition should be reflected in practice, providing a human to normal environmental conditions right environment necessary for the full and healthy lives. And thus it is necessary to take into account that environmental safety because of its relevance and importance for Central Asia is among the most important problems.

Despite this, recent decades have seen a dramatic change in environmental awareness and human thinking that environmental problems aroused a sense of responsibility towards present and future generations, these feelings are not adequately reflected in practice. Adverse environmental problems that have appeared in recent decades, both worldwide and in Central Asia, especially in the territory borders of Uzbekistan and Tajikistan, have created a situation of environmentally critical nature, and this has a negative impact on one of the important elements - "the right to life "- the ecological security of the peoples of these regions. This is the main reason for the functioning of the Tajik Aluminum Plant (TadAZ), built as a major industrial site in 1975 in the city of Tursunzade, design capacity is 517 thousand tons of aluminum per year. For 40 years, this plant emits into the air parts of the territory belonging to Surkhandarya region, which borders with Tajikistan, more than 40 kinds of harmful substances, namely in the large amount of hydrogen fluoride, carbon monoxide, nitrogen dioxide, sulfur dioxide and hydrocarbons. Due to the fact that the object is located at a distance of 10 kilometers from the Surkhandarya region Denov areas Sariasii and Uzun, the gases output by the plant, poison the flora and fauna, agriculture crops and seriously affect the health of more than 700 thousand population of the country.

Although done some work on the implementation of the Agreement between the Government of the Republic of Uzbekistan and the Government of the Republic of Tajikistan on cooperation in improving the environmental situation in the area of the negative impact TadAz, signed on 17 November 1994 at Tashkent, was not implemented program of research and technical work to improve the TadAz ecological condition for 1996-2000., the funding that was provided by the plant. In addition, in recent years the plan between the Government of the Republic of Tajikistan and the company "Rusal" of the Russian Federation building more new plants planned for the production of primary aluminum with a design capacity of 170 thousand tons per year is alarming.

2007 Decree of the President of the Republic of Tajikistan TadAz renamed the State Unitary Enterprise "Tajik Aluminum Company". The decision to rename the plant was made in order to improve the rating of the aluminum industry of Tajikistan in the international arena, as well as the continuation of reforms initiated by the company. The strategic objectives of the plant envisages a further increase in production, the introduction of new energy efficient and economically sound technologies, improvement of product quality.

At the same time, waiting for a major reconstruction of treatment facilities is not justified. As with previous years, emissions of pollutants into the atmosphere, which annually amount to about 22 thousand tons per year, including 120 tons of hydrogen fluoride continue to have a negative impact on the health status of the population and environmental degradation of some areas of Surkhandarya region, cause economic damage to agricultural production.

Aggravates the situation and climatic conditions of the region, which contribute to the accumulation of pollutants in the atmosphere. Observations of the level of air pollution conducted Uzhydromet showed that the content of hydrogen fluoride in the air Sariasijsky area ranged 0.8-1.8 MPC, exceeding hygienic norms in some cases, 2 times.

\footnotetext{
${ }^{2}$ www.mirnov.ru
} 
Air pollution and amplified by summation between sulfur dioxide and nitrogen dioxide, hydrogen fluoride and sulfur dioxide ${ }^{3}$.

In recent years, this has led to increase in diseases of the circulatory, respiratory, stomach, especially endocrine and ontological diseases. Tajik Research Institute of Preventive Medicine, Ministry of Health of the Republic of Tajikistan also studied the state of health of the population in the region, pollution from the Tajik Aluminum Plant, and research results from the Tajik and Uzbek experts agree ${ }^{4}$.

It should be emphasized that the environment does not recognize the state and administrative boundaries, and the efforts of one or more states within their country or region can not prevent ecological crisis and to give tangible results in this area, as it is a global phenomenon and is now ensuring environmental security requires the formation of international relations, maintain and improve sufficiently the quality of the environment for living organisms, and humanity, as well as the integration of states in the system of environmental policy for the uniform development of the countries and peoples of the region.

Uzbekistan after independence builds democratic rights of the state and open civil society, ensuring the observance of human rights and freedoms, the formation of a socially and ecologically oriented market economy, a full-fledged integration into the world community. To this end, Uzbekistan joined the international UN institutions, the OSCE, ratified 9 environmental conventions and related protocols of their development, signed 12 international agreements on cooperation in the field of environmental protection. Accession and ratification of international legal instruments in the field of environment and development - an important element of performance by Uzbekistan of its obligations to the international community.

Most of the environmental problems in Uzbekistan are transboundary. These include acute water shortages, billions of tons of industrial waste, land degradation, loss of biodiversity. And their solution requires joint efforts of all the neighboring states. In this respect, should play a role, such cross-border convention UN European Economic Commission (UNECE), as the Convention on Transboundary Air Pollution on long distances, the Convention on the Transboundary Effects of Industrial Accidents, Convention on Environmental Impact Assessment in a Transboundary Context, the Convention for the Protection of and use of transboundary Watercourses and international lakes.

In this case, every day increases the space requirement and importance of governmental and nongovernmental organizations, especially the UN. In 1972, in a special Stockholm Conference on Human Environment, adopted a Declaration regarding plans for international environmental principles and action, and laid the foundation of the basic kind of streamlining the international legal relations - regional environmental movements. It was the Stockholm conference laid the foundations for a balanced and integrated approach to the global level of the whole range of environmental problems. The adopted solutions in the Swedish capital have given a powerful impetus to international environmental cooperation, predetermining the rapid development of international environmental law and setting new parameters of the United Nations environmental activities. In addition, the conference had an impact on the internal politics of many countries, national priorities which were absent before environmental issues. After Stockholm en masse began to develop national environmental programs, and mechanisms were established to implement them.

According to her, the international environmental cooperation provides for the implementation in the areas of interstate and international collaborations of environmental protection and the promotion of good practices, the development of science-based measures for the protection of nature in a particular region or a limited area, the implementation of universal solutions to global environmental problems through the UN and the government, nongovernment organizations. In general, environmental protection at international level is not only environmental requirements, they should be formed including confidence and social and political and economic demands. Because environmental problems are interlinked with global issues such as human rights, the economy, energy, food and education. Therefore, the Republic of Uzbekistan pays great attention to environmental issues, especially taking into

\footnotetext{
${ }^{3}$ National report on the state of environment and use of natural resources in the Republic of Uzbekistan. T .: «Chinor ENK», 2008, p.28.

${ }^{4}$ Akhmedov AA Results of the study of public health. // Sanitation and hygiene. Dushanbe, 2001, № 2, p.35-38.
} 
account human rights, cooperation and collaboration of all countries of the world, especially with the Central Asian region. Uzbekistan cooperates in matters of regional integration, both with individual members of the CIS - on the basis of bilateral agreements (Russia, Ukraine, Kazakhstan, Georgia), and with the Interstate Ecological Council. In 2012, the Heads of State in Astana - Kazakhstan and Uzbekistan attaches great importance to collaborative and principled positions on issues of rational use of water and energy resources in Central Asia and stressed the need to resolve all issues in this area, including the construction of new hydraulic structures on transboundary rivers, in according to the generally recognized rules of international law and taking into account the interests of all states in the region ${ }^{5}$.

The Programme of Action for the CIS development until 2025, prepared and signed by the Heads of State in 2000, provides for a series of measures for environmental protection (environmental monitoring, environmental security, unified system of classification of industrial wastes and their marking, etc.).

Considering that the protection of the natural environment, environmental security in Central Asia depends on the desire of a State, as well as conducting joint coherent environmental policy states, the development of economic and legal mechanisms of the creation of social and cultural conditions, states in the region must work together to seek to achieve these goals.

Also, you should take into account that States parties to international co-operation to ensure environmental safety in the region should respect the rules on environmental protection - international environmental principles, that is, these rules should be based on international law and should serve as an indication in the development of legal norms, relations and mechanisms. As mentioned in the second article of the UN Charter, we must not forget that the principles of international relations, mandatory for members of an international organization of states, are based on international environmental principles.

It should be noted that these principles are reflected in the documents of the United Nations Conference on Environmental Protection in Stockholm (1972) and for the protection of biodiversity in Rio de Janeiro (1992), the outcome of the Helsinki European security (1975), in World Charter for nature, they are listed separately principles do not harm the environment outside the jurisdiction of the state. In particular, according to this principle, each State or entity of international law should be without prejudice to actions in the territory of their region or country under control, otherwise they are responsible for their actions.

But, unfortunately, in the Republic of Tajikistan to any specific political and economic conditions, this rule does not have his strength. Since aluminum plant located in Tursunzade Tajikistan is a major source of environmental pollution in Central Asia, on the part of international organizations, including the Programme of the United Nations Environment Programme (UNEP), the World Health Organization (WHO), United Nations Development Programme Nations (UNDP), the World meteorological organization (WMO), the United Nations Industrial development organization (UNIDO), as well as two of its regional commissions: economic Commission for Europe (UNECE) and the economic and social Commission for Asia and the Pacific (ESCAP) should be carried out comprehensive integrated environmental impact assessment and its results need to develop evidence-based measures of environmental protection and in accordance with decisions of the United Nations must necessarily applied in practice. And also, of course, according to the UN decision, in these circumstances, the state - Tajikistan, international legal responsibility and sanction in the form of economic needs to be applied, the political, social or cultural "boycott" and the matter fundamentally must deal directly with the United Nations.

Based on the above, in order to improve environmental protection and environmental security in Central Asia need to allow the following international legal issues:

To establish a Central Asian environmental commission of the United Nations (UN CAEPCO), as an international clearing-controlling body for environmental protection and ecological safety;

A special program (CAEPCO) in-depth study of the processes of harmful emissions of hazardous sources on the environment and human health in order to develop specific measures to improve the situation in the region;

To create a single regional network of environmental monitoring, prediction and control of the protection of the environment;

To form a regional ecological security system;

Create a system of protection of the region states of transboundary pollution;

Systematically organize international forums to discuss environmental problems in the region and assist in attracting funding from international organizations.

\footnotetext{
${ }^{5}$ «National word», 8 September, 2012.
} 